\title{
Modeling Comparison of Monopile and Elevated Pile Foundation for Offshore Wind Turbines
}

\author{
Liyuan Liu, Hongming Chi, Hao Zhang, Yong Wu, Yongxiang Wu
}

Long Yuan (Beijing) Wind Power Engineering \& Consulting CO., LTD, Beijing, china

Keywords: monopile; elevated pile foundation; $p$-y curve; model comparison

Abstract: In order to analyze the bearing capacity of monopile foundation and elevated pile foundation for offshore wind turbines, models were established using finite element analysis software Abaqus and design software FDOW. Bearing capacities of the monopile foundation and elevated pile foundation were compared and analyzed, under the premise of same geometry size and boundary conditions. Two types of Abaqus monopile foundation models were established respectively using beam and shell element. The Abaqus elevated pile foundation model was established using shell element for the steel pipe pile and the solid element for the concrete pile cap. Soil constraints were simulated using p-y curve method. In the FDOW models, soil constraints were simulated using p-y curve method as well. Stress under extreme conditions and deformation under normal conditions were calculated respectively. The calculated results of Abaqus and FDOW were closer, but there are some differences as well. Considering the importance of wind turbine foundations, at least two software should be used when design, and take the unfavorable results as design guidance, which may provide a theoretical basis and recommendations for the future design.

\section{Background}

Monopile foundation. Monopile foundation is the simplest form of the offshore wind turbine foundation structures, and it is the most widely used form currently. It is usually made of welded steel pipe which is manufactured by curved steel plate. The connections between the wind turbine tower and the monopile foundation can be welded connections or sleeve connections. The sleeve connection is also known as the transition segment structure of the monopile foundation. Grouting connection is generally used in the sleeve connection. The wind turbine loads and environmental loads are undertaken by the resistance of the monopile side soil.

Monopile foundation has the characteristics of high bearing capacity, small settlement, good uniformity and good seismic performance. Monopile foundation is able to better withstand vertical load, horizontal load, the vibration and dynamic load of the wind turbine operation. And it can penetrate to deeper bearing stratum. With the increase of steel production, the development of steel pipe pile anticorrosion technology and the development of new materials, especially for the harsh offshore environmental and geological conditions, the monopile foundation has been widely used in the offshore, onshore wind farm and harbor engineering with its larger bearing capacity, relatively simple construction technology, small amount of drainage and good mechanical performance。

Elevated Pile Foundation. The elevated pile foundation is designed reference to the pier structure in the port engineering or the pier of the sea-crossing bridge. The general form of the piles is oblique. The elevated pile foundation has many advantages, such as the mature technology of connection between the foundation and the turbine tower, the large rigidity of the whole foundation, the mature construction equipment and experience, lower steel consumption, etc. However, the large volume of concrete structure is complex, and its construction period is long. Also the factors such as pile driving inconvenience caused by the oblique steel piles are also restricted to the application of elevated pile foundation. 
Analysis method of soil constraints. The foundation of the wind turbine is not only subjected to the vertical load, but also the horizontal load and bending moment caused by the environmental load. The calculation method of the horizontal bearing capacity of the pile foundation mainly includes the elasticity analysis method, the composite elastic-plastic subgrade reaction method and the numerical method. Under the condition of large horizontal load, the elastic plastic model is generally used, and the p-y curve theory based on the composite foundation reaction method is widely used to simulate the soil constraints. P-y curve method can more accurately imitate the nonlinear property of the soil, and it is the calculation method which is widely accepted by engineering and academia circles.

Since the 1980s, our country has begun to study the p-y curve. Currently, researches and engineering design at home and abroad are still mainly based on the description of p-y curve in API specifications of American Petroleum Institute. Similar stipulations are also in the DNV specifications. Companies such as China National Offshore Oil Corporation also adopt API specification of American Petroleum Institute as the standard release of petroleum and natural gas industry.

Therefore, based on finite element software Abaqus and design software FDOW, the p-y curve method (based on API specification) is used to simulate the soil constraints, and the mechanical properties of the monopile foundation and elevated pile foundation under the design load are compared and analyzed.

\section{Finite Element Model}

The analysis of this paper is based on monopile and elevated pile foundation, two forms of wind turbine foundations of two testing machines in a certain offshore wind farm.

For a certain direction scale (the longitudinal direction) is obviously larger than the other two directions, and the structure gives priority to the longitudinal stress, then beam element can be used. In the beam element, it is assumed that the cross section of a beam is perpendicular to the axial direction and the cross section remains plane when it is deformed. Considering that the shape of the circular tube's cross section may change under the effect of horizontal loads because of the counterforce which soil causes to the pile sides, the horizontal section assumption no longer valid any more. Therefore, in Abaqus modeling, for monopile foundation, under the same load and soil constraint, beam element and shell element are used respectively, and p-y curve method is adopted for modeling in soil constraint. The results of Abaqus were compared to the FDOW results under the extreme and normal operating conditions.

For elevated pile foundation, the steel-pipe pile model adopts the shell element, the concrete pile cap adopts the solid element, and the soil constraint adopts the p-y curve method for modeling in Abaqus. Similarly, the results of Abaqus were compared to the FDOW results under the extreme and normal operating conditions.

The steel-pipe pile is considered as the beam element in the FDOW model, and the p-y curve method is also used for soil constraint. The stress and deformation are respectively calculated under the extreme and the normal operating condition.

Basic Parameter. The monopile model constitutes of two parts of the transition section and the pile body itself. The transition section has a height of $10 \mathrm{~m}$ and diameters of $4.5 \mathrm{~m}$ to $6 \mathrm{~m}$ varying from the upper part to the lower part, and a thickness of $60 \mathrm{~mm}$. The pile body has a length of $70 \mathrm{~m}, \mathrm{a}$ diameter of $6 \mathrm{~m}$ and a thickness of $70 \mathrm{~mm}$. The pile is $21 \mathrm{~m}$ long above the silt surface and $49 \mathrm{~m}$ long below the silt surface. Material Q345 is selected for the monopile.

The elevated pile foundation consists of two parts of concrete cap and steel-pipe piles. The 
concrete cap has a diameter of $18 \mathrm{~m}$ and thickness of $4.5 \mathrm{~m}$. The elevation of the cap top is $7 \mathrm{~m}$, and C45 concrete is selected as the material. The altitude of the silt surface is $-24 \mathrm{~m}$. There are 10 steel-pipe piles totally, and the diameter of each one is $2.1 \mathrm{~m}$. The arrangement radius diameter of piles is $6.9 \mathrm{~m}$, and its slope is $6: 1$. The total length is $100 \mathrm{~m}$. The thickness of the upper $40 \mathrm{~m}$ pile is $30 \mathrm{~mm}$, and the thickness of the lower $60 \mathrm{~m}$ pile is $26 \mathrm{~mm}$. The material Q345 is used as well.

It is supposed to adopt the extreme loading condition for the strength checking and the normal operating condition for the deformation checking. The main purpose of this paper is to make a comparison between the models of software Abaqus and FDOW. To avoid the difference of environmental load, in the present modeling only the wind turbine load at the bottom of tower is added into the finite element model. The load value of the monopile foundation is shown in Table 1, and the load value of the elevated pile foundation is shown in Table 2:

Table 1 The Load Case of the Monopile Foundation and Its Load Value1

\begin{tabular}{lllll}
\hline & $F_{\mathrm{x}}(\mathrm{kN})$ & $F_{\mathrm{z}}(\mathrm{kN})$ & $M_{\mathrm{y}}(\mathrm{kN} \cdot \mathrm{m})$ & $M_{\mathrm{z}}(\mathrm{kN} \cdot \mathrm{m})$ \\
\hline Extreme operating condition & $1.35 \times 10^{3}$ & $3.51 \times 10^{3}$ & $-1.04 \times 10^{5}$ & $-5.64 \times 10^{3}$ \\
Normal operating condition & $0.90 \times 10^{3}$ & $2.60 \times 10^{3}$ & $-6.73 \times 10^{4}$ & $-7.64 \times 10^{3}$ \\
\hline & Table 2 The Load Case of Elevated piles and The Load Value 2 & $M_{\mathrm{z}}(\mathrm{kN} \cdot \mathrm{m})$ \\
\hline & $F_{\mathrm{x}}(\mathrm{kN})$ & $F_{\mathrm{z}}(\mathrm{kN})$ & $M_{\mathrm{y}}(\mathrm{kN} \cdot \mathrm{m})$ & $1.64 \times 10^{4}$ \\
\hline Extreme operating condition & $2.32 \times 10^{3}$ & $7.95 \times 10^{3}$ & $-1.88 \times 10^{5}$ & $7.64 \times 10^{3}$ \\
\hline Normal operating condition & $1.08 \times 10^{3}$ & $5.30 \times 10^{3}$ & $-8.53 \times 10^{4}$ &
\end{tabular}

Parameters of every soil layer is shown in Table 3. According to API specification formulas, the p-y curve of every soil layer was derived. The curves are used as parameters input into the nonlinear spring restraint on the pile body in the Abaqus finite element software to simulate the interaction between soil and steel-pipe piles. In the FDOW software will automatically calculate the soil restraint according to the $\mathrm{p}-\mathrm{y}$ curve method by inputting the soil parameters.

\begin{tabular}{|c|c|c|c|c|c|c|c|}
\hline \multirow{2}{*}{ Soil layer } & \multirow{2}{*}{$\begin{array}{l}\text { Layer } \\
\text { Depth } \\
(\mathrm{m})\end{array}$} & \multirow{2}{*}{$\begin{array}{l}\text { Natural } \\
\text { Density } \rho \\
\left(\mathrm{g} / \mathrm{m}^{3}\right)\end{array}$} & \multirow{2}{*}{$\begin{array}{l}\text { Ultimate lateral } \\
\text { resistance } \\
\mathrm{q}_{\text {sik }}(\mathrm{kPa})\end{array}$} & \multirow{2}{*}{$\begin{array}{l}\text { Ultimate tip } \\
\text { resistance } \\
\mathrm{q}_{\mathrm{pk}}(\mathrm{kPa})\end{array}$} & \multicolumn{2}{|c|}{$\begin{array}{l}\text { Triaxial consolidated undrained } \\
\text { Shear strength (UU) }\end{array}$} & \multirow{2}{*}{$\begin{array}{l}\text { Friction } \\
\text { Angle } \\
\left({ }^{\circ}\right)\end{array}$} \\
\hline & & & & & $\mathrm{C}_{\mathrm{u}}(\mathrm{kPa})$ & $\psi_{\mathrm{u}}\left({ }^{\circ}\right)$ & \\
\hline Medium Gravel Sand & 8 & 2.01 & 50 & 3500 & 0 & 32 & $25^{\circ}$ \\
\hline Clay & 26.4 & 1.94 & 55 & 1500 & 32 & 6 & $35 \mathrm{kPa}$ \\
\hline Silty clay & $>65$ & 1.88 & 40 & 1300 & 30 & 6 & $30 \mathrm{kPa}$ \\
\hline
\end{tabular}

Finite element modeling. For monopile foundation, the beam element model adopts B31 beam element in the Abaqus finite element software, and the cross section adopts the form of a pipe to define the external diameter and thickness. Because the diameter of the upper transition part is gradually change from $4.5 \mathrm{~m}$ to $6 \mathrm{~m}$, the transition part is divided averagely into ten sections in the beam element model. Every section takes the diameter of the middle section so as to approximately stimulate the changes of the cross section, as shown in Figure 1. The non-linear spring constraint is applied on the pile sides under the silt surface, as shown in Figure 2. The shell element model adopts the S4R shell element in the Abaqus finite element software, which can define the wall thickness respectively. The springs should be exerted at all element nodes as shown in Figure 3, in order to guarantee the happening of stress concentration at the constraint node. The degrees of freedom of the top round border were coupled to a reference point and the loads were imposed on this reference point. 


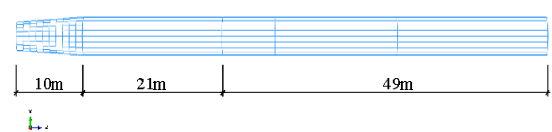

Fig. 1 Monopile Model-Beam Element

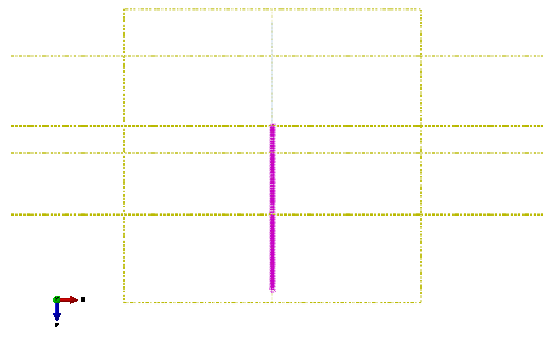

Fig. 2 Beam Element Constraints

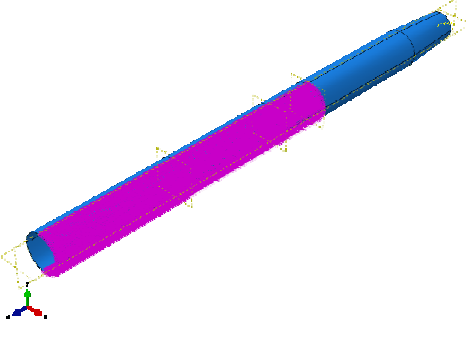

Fig. 3 Shell Element Constraints1

For elevated pile foundation, the C3D8R solid element is adopted for the concrete cap and S4R shell element for the piles in Abaqus model. The non-linear spring constraint is imposed on on the side of the piles under the silt surface, as shown in Figure 4. Because of the direction difference of steel piles, the setting of spring constraints is complicated. When exerting soil constraints, the steel pipes were divided according to dip direction of each pile, and the non-linear spring constraint is imposed on half of the section in the load direction. After enlarging, detailed part is as shown in Figure 5.

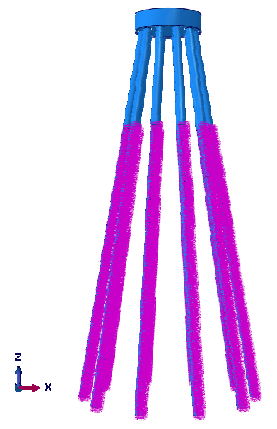

Fig. 4 Spring constraint imposed on elevated pile model

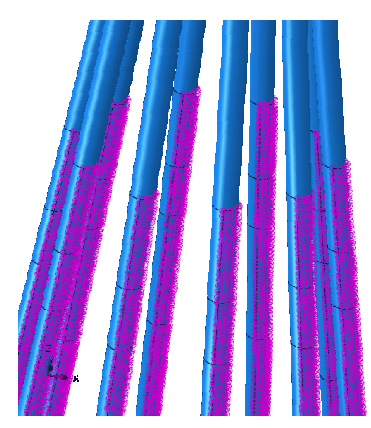

Fig. 5 Detailed drawing of pile constraint

FDOW modeling. FDOW is a design software for offshore wind turbine foundation. When modeling, the wind turbine parameters, geological data, environmental data, foundation parameters, auxiliary design data and so on should be put in and the calculation and analysis of the structural strength, stability, displacement of the pile foundation can be carried out. The specific parameters and calculation methods won't be stated in detail here.

\section{Analysis Results Comparison}

Monopile foundation results. For monopile foundation, the biggest stress at the body part of the pile is near the silt surface, and the horizontal displacement generally focused should be at the bottom of the tower and the silt surface.

In the Abaqus beam element model, the overall stress nephogram under extreme operating condition is shown in Figure 6 and the local stress nephogram of silt surface is shown in Figure 7; the overall displacement nephogram under normal operating condition is shown in Figure 8 and the local displacement nephogram of the silt surface is shown in Figure 9.

In the Abaqus shell element model, the overall stress nephogram under extreme operating condition is shown in Figure 10 and the overall displacement nephogram under normal operating condition is shown in Figure 11. 


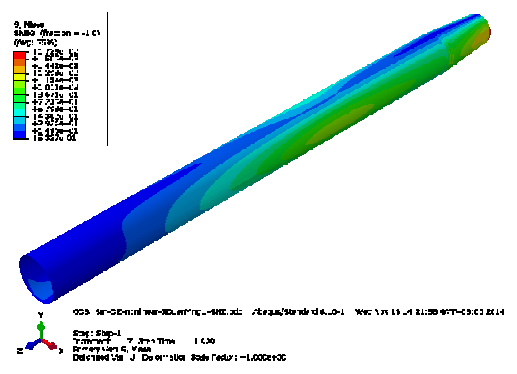

Fig. 6 Overall stress of the shell element model

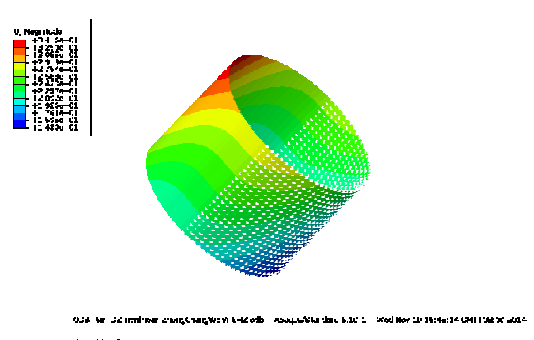

然:

Fig.9 Slit surface local displacement of the shell element model

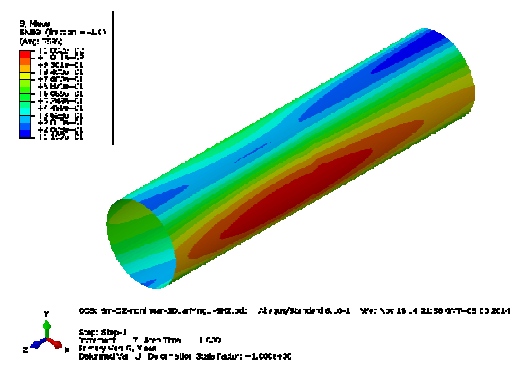

Fig.7 Slit surface local stress of the shell element model

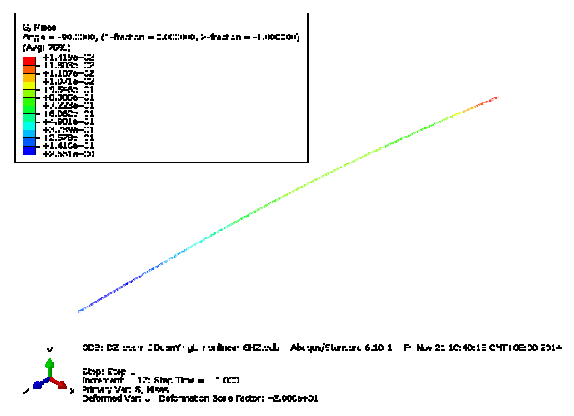

Fig. 10 Stress of the beam element model

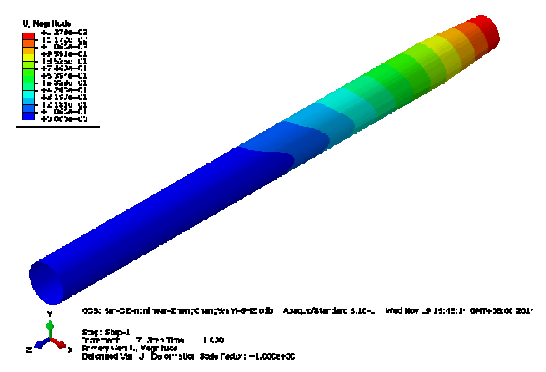

Fig. 8 Overall displacement of the shell element model
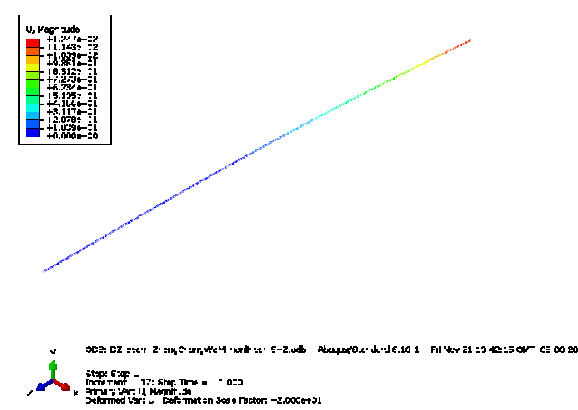

Fig.11 displacement of the beam element model

The calculation results are shown in Table 4. Abaqus beam element model's stress and displacement are smaller than the shell element model's. The calculation results of Abaqus and FDOW are relatively close, and the stress of Abaqus shell element model is a little bit larger while that of the beam element model is smaller. Besides, displacement results of Abaqus are larger than FDOW.

Table 4 Calculation results comparison of the of monopile foundation 4

\begin{tabular}{ccccc}
\hline \multirow{2}{*}{ Project } & Location & Shell element model & Beam element model & FDOW \\
\hline $\begin{array}{c}\text { Maximum stress under extreme } \\
\text { operating conditions }\end{array}$ & Near the silt surface & $109.2 \mathrm{MPa}$ & $91.98 \mathrm{MPa}$ & $99.92 \mathrm{MPa}$ \\
$\begin{array}{c}\text { Maximum displacement under } \\
\text { normal operating Conditions }\end{array}$ & Bottom of the tower & $127.9 \mathrm{~mm}$ & $124.7 \mathrm{~mm}$ & $103.64 \mathrm{~mm}$ \\
\hline
\end{tabular}

Elevated pile foundation results. In Abaqus model, the overall stress nephogram under extreme operating condition is shown in Figure 12 and the local stress nephogram on silt surface is shown in Figure 14; the overall displacement nephogram under normal operating condition is shown in Figure 13 and the local displacement nephogram on silt surface is shown in Figure 15.

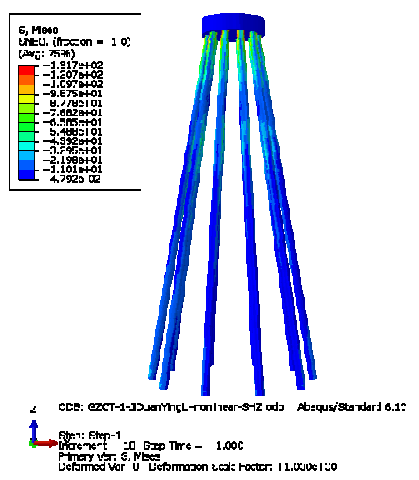

Fig. 12 Overall stress of elevated pile foundation2

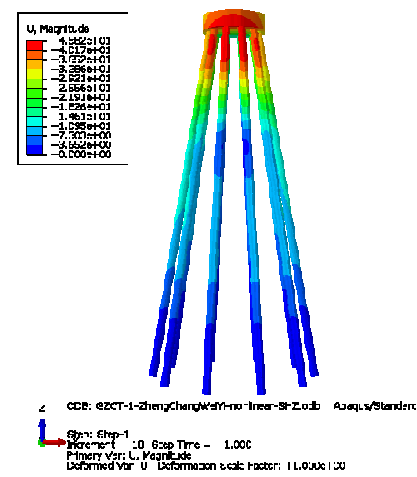

Fig. 13 Overall displacement of elevated pile foundation
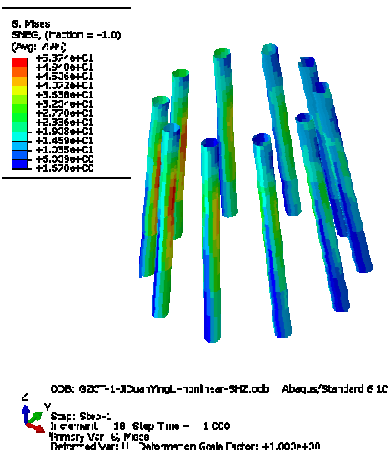

Fig.14 Slit surface local stress of elevated pile foundation

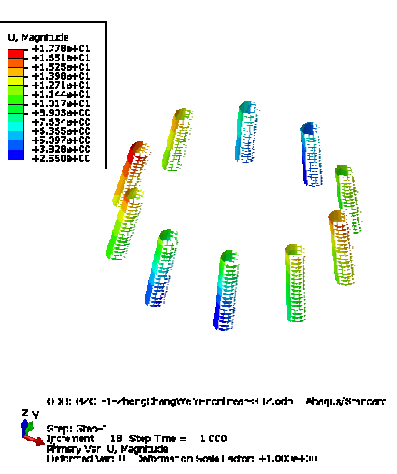

Fig.15 Slit surface local displacement of elevated pile foundation 
The calculation results of the Abaqus finite element model and the FDOW are shown in Table 5. It can be seen that under extreme and normal operating conditions, the stress and displacement results of Abaqus and FDOW are very close.

Figure 5 Calculation results comparison of the elevated pile foundation5

\begin{tabular}{clcc}
\hline Project & Location & Abaqus model & FDOW model \\
\hline $\begin{array}{c}\text { Maximum stress under extreme } \\
\text { working conditions }\end{array}$ & Near the silt surface & $62.12 \mathrm{MPa}$ & $63.35 \mathrm{MPa}$ \\
Maximum displacement under & Bottom of the tower & $45.73 \mathrm{~mm}$ & $50.18 \mathrm{~mm}$ \\
normal operating conditions & Near the silt surface & $11.782 \mathrm{~mm}$ & $9.67 \mathrm{~mm}$ \\
\hline
\end{tabular}

\section{Conclusion}

Through modeling of monopile and elevated pile foundations respectively by Abaqus finite element software and FDOW software, and the analysis of bearing capacities of the two foundation forms, the following conclusions and suggestions are obtained:

(1) For monopile foundation, stress and displacement results of Abaqus beam element model are both smaller than those of shell element model. The shell element model can consider the stiffness of steel tube section and its deformation. It tends to be safer for foundation design;

(2) For monopile foundation, Abaqus model results are relatively close to results of FDOW and the stress of Abaqus shell element model is a little bit larger while that of the beam element model is smaller. Besides, displacement results of Abaqus are larger than FDOW;

(3) For elevated pile foundation, the stress and displacement results of Abaqus and FDOW are very close.

(4) In consideration of the importance of the offshore wind turbine foundations and the difference of calculating parameters adopted by different analysis software, it is suggested to use at least two kinds of software when design and take the disadvantages as the design basis.

\section{Reference}

[1] Wang Wei, Yang Min. Basic design theory and engineering application of offshore wind turbine foundation [M]. Beijing: China Architecture \& Building Press, 2013: 18-24

[2] Li Wei, Chen Fabo, Lv Na, etc. The applicability study of $p$-y curve method in the pile soil effect calculation of the offshore wind power basis[J]. Water Power, 2011, 37 (10) : 96-99

[3]Wang Ruifeng. The horizontal bearing characteristic study of the major diameter steel-pipe pile [D]. Tianjin: Tianjin University, 2011

[4] McClelland B, Focht J A. Soil modulus for laterally loaded piles. Transactions of the American Society of Civil Engineers[J]. 1958, 123(2954): 1049-1063

[5] Matlock H. Correlations for design of laterally loaded piles in soft clay [C]. Offshore Technology Conference, 1970: 577-594

[6] Reese L C, Welch R C. Lateral loading of deep foundation in stiff clay[J]. Journal of Geotechnical Engineering Division, American Society of Civil Engineers, 1975, 101(6):633-649

[7] Zhang Shuyu. Research on $p-y$ curve of the dead load of the horizontal bearing pile [D]. Nanjing: Hehai University, 2001

[8] Yang Guoping, Zhang Zhiming. Research on $p$-y Curve of the Laterally Bearing Pile Under the Condition of Large Displacement [J]. Port \& Waterway Engineering, 2002, 342 (7): 40-45

[9]Sun Dongmei. The Research on $p-y$ Curve of Laterally Loaded Large Diameter Piles [D]. Tianjin: Tianjin University, 2004 
International Forum on Energy, Environment Science and Materials (IFEESM 2015)

[10]Rowe P W. The Monopile Subject to Horizontal Force [J]. Port \& Waterway Engineering, 1956,6(2):70-85. 